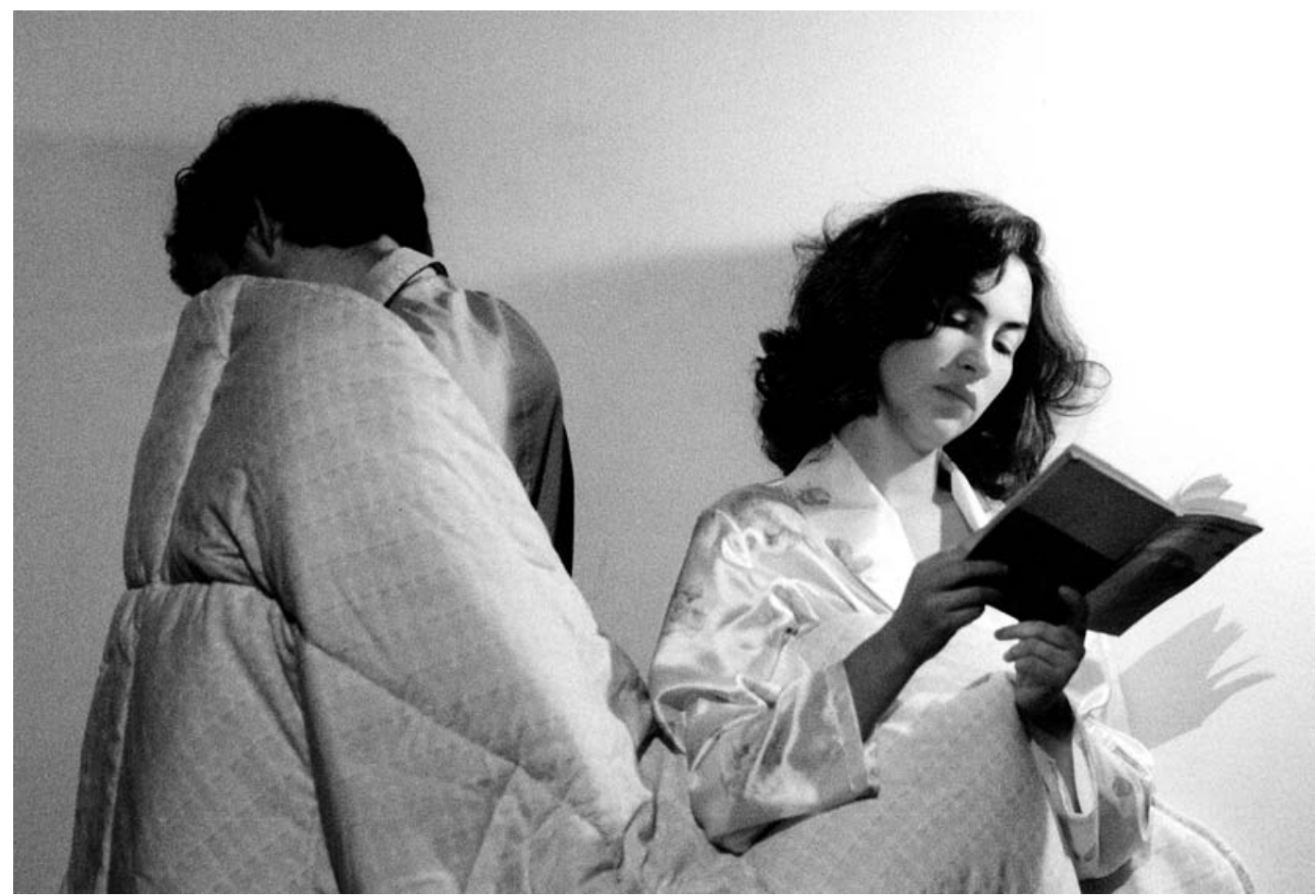

Nunca nada de ninguém de Luisa Costa Gomes, enc. Ana Tamen, Acarte, 1991 (Paulo Filipe e Rita Blanco), fot. José Manuel.

\title{
As mulheres (in)visíveis de Luísa Costa Gomes ${ }^{1}$
}

Vanessa Silva Pereira éleitora de português na Universidade de Manchester

\section{Vanessa Silva Pereira}

A centralidade atribuída aos elementos do sexo feminino, em todas as fases da sua produção, faz de Nunca nada de ninguém um caso de excepção no teatro português. Este texto "no feminino", que foi encomendado por Ana Tamen e escrito por Luísa Costa Gomes, é, nos três interlúdios que precedem os três actos da peça, quase inteiramente povoado por mulheres ${ }^{2}$. Neste artigo ${ }^{3}$, usando das palavras de Elin Diamond que citamos em epígrafe, vamos avaliar não só da "visibilidade" que adquirem as personagens femininas de Nunca nada de ninguém, mas ainda do tipo de visibilidade que Ihes é "permitida" enquanto personagens individuais. A problemática da individualidade feminina vai ser relacionada com as caracteristicas patriarcais do discurso que determinam a natureza de excepção deste texto (porque construido essencialmente por mulheres). Utilizaremos para esta discussão, sobre a natureza do discurso patriarcal e do sujeito feminino, as noções definidas por Irigaray no seu artigo "The power of discourse and the subordination of the feminine". Fazendo uso das noções de feminilidade, ironia e patriarcado, vamos explicar como a autora abre um espaço irónico nos três interlúdios que reforça a visibilidade das mulheres presentes em palco, sem deixar ao mesmo tempo de enfatizar a sua condição feminina de invisibilidade social, histórica e política.

Se é certo que encontramos nos três interlúdios desta
The lighted stage queries the world of "permissible" visibility: what can, and more importantly, what cannot be seen. (Diamond 1988: 192).

peça a presença quase exclusiva das mulheres, chegamos a saber muito pouco acerca das suas motivações enquanto personagens individuais. No primeiro interlúdio, diz-se: "Em palco estão cinco mulheres, (...) o primeiro interlúdio é constituído pelos discursos destas cinco mulheres, discursos curtos, entrecortados de pausas, interrompidos por outros, retomados, abandonados; o que é necessário manter é o fluir das palavras e das histórias" (Gomes 1991: 13). Os discursos "curtos" e "entrecortados", as constantes "pausas" e "interrupções", dificultam ao espectador a tarefa de diferenciação das personagens já que a "fluidez" do discurso (sublinhada no original), faz confundir as falas e as experiências de cada personagem. Esta situação tornase ainda mais evidente se pensarmos que as personagens em vez de individualmente nomeadas são simplesmente numeradas, de uma a quinze, do primeiro ao último interlúdio. Estas personagens problematizam ainda a sua individualidade não apenas na forma como falam mas naquilo "de que" falam. As cinco mulheres, interlúdio após interlúdio, fazem outras personagens falar através de si: os filhos, maridos ou companheiros. Este facto contribui para que a sua individualidade se torne problemática, sendo mais facilmente compreendido se recorrermos às palavras de Irigaray sobre a posição das mulheres no discurso patriarcal: "o homem nunca foi reduzido a uma simples função reprodutora" (...) enquanto que a mulher
10 titulo deste artigo parafraseia o artigo de Elin Diamond, "(In)visible Bodies in Churchill's Theatre", do qual é também retirada a epigrafe.

2 Nunca nada de ninguém estreou a 7 de Novembro de 1991 no ACARTE / Centro de Arte Moderna da Fundação Calouste

Gulbenkian. 0 espectáculo foi encenado por Ana

Tamen e no elenco

encontravam-se Rita Blanco, Paulo Filipe, Lidia Franco, João Lagarto, Nuno Melo, Teresa Roby e Alexandra Rosa.

Este artigo decorre da investigação para a tese de mestrado Voicing the Invisble: gender, character and discourse in Luisa Costa Gomes and Caryl Churchill, concluida na Universidade de Manchester (2006). 


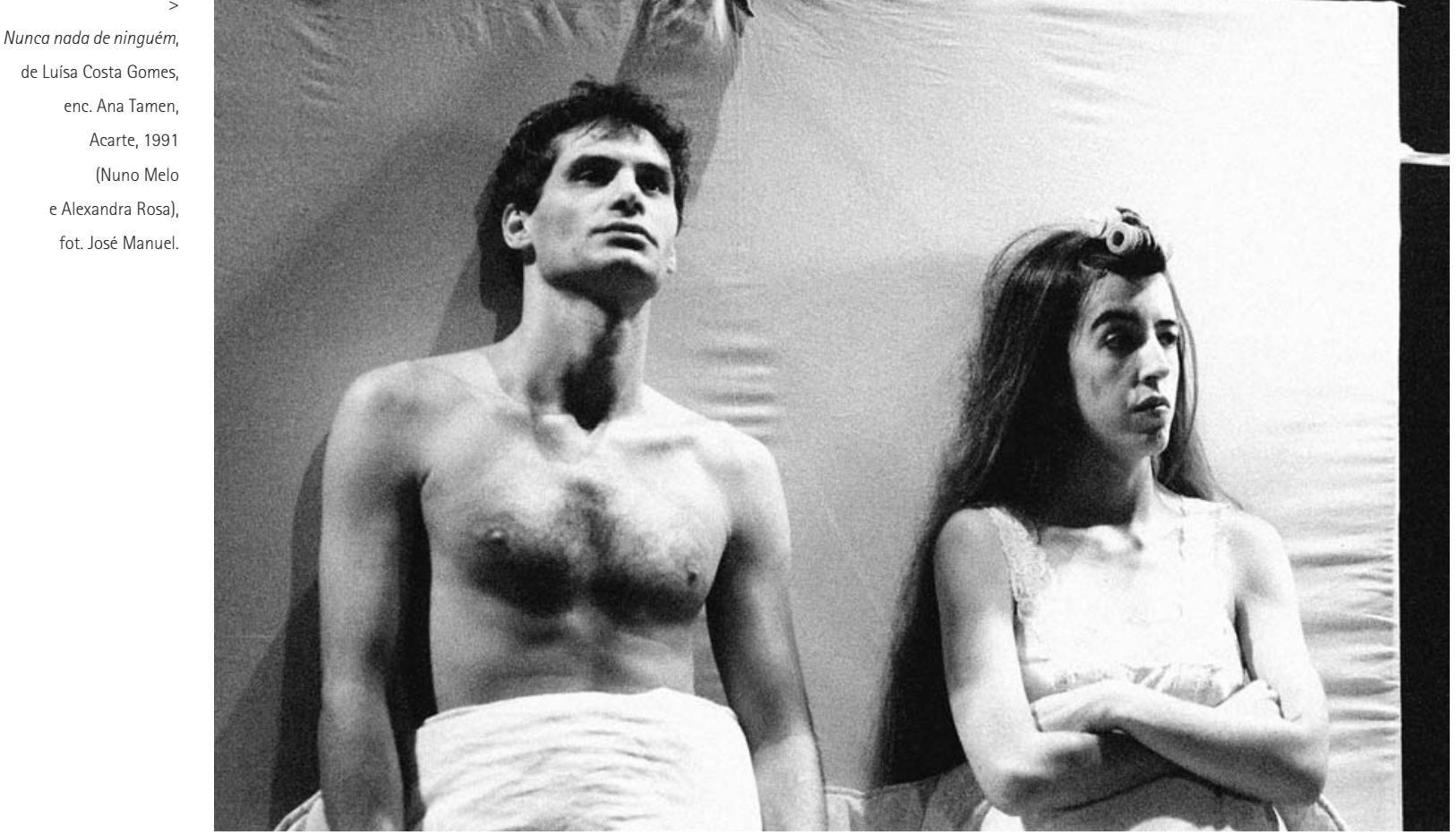

"nunca foi senão mãe" (Irigaray 1985: 83, tradução minha). Ao fazerem depender a sua existência da condição de mães e esposas, as personagens femininas relembram ao espectador as dificuldades, sublinhadas pela citação de Irigaray, da representação autónoma e individual das mulheres no discurso patriarcal.

A problemática da individualidade das personagens femininas relaciona-se, nesta peça, com os elementos contraditórios que simultaneamente afirmam e fazem perigar a visibilidade destas mesmas personagens. 0 espectador vê um grupo de mulheres que, em vez de susterem a esperada centralidade, remetem

constantemente para um espaço de acontecimentos que está além do palco. Cria-se um desfasamento (entre o que se espera e o que de facto acontece, entre o que se diz e o que se quer dizer ou entre o que se diz e o que se vê) que remete para o espaço irónico do texto. Este espaço está dependente, como no primeiro interlúdio, da representação de personagens ausentes nos discursos das personagens femininas em palco, e, no segundo interlúdio, das chamadas personagens "invisiveis". Escreve a autora, no segundo interlúdio: "No palco está uma mulher que, de frente para o público, na esquerda centro, empurra um baloiço onde não há ninguém. Fala para uma pessoa invisivel, o ex-marido, que estaria à frente do baloiço, enquanto dá balanço" (Gomes 1991: 61). Aqui, uma situação familiar (um jardim infantil, uma conversa entre ex-marido e mulher, uma criança que anda de baloiço) deixa de o ser, porque se produz um estranhamento na acção através da presença de personagens invisiveis, que tornam distante uma cena de contornos realistas. A secundarização discursiva das personagens que estão física e visualmente presentes, relativamente àquelas que apenas se encontram ali nos fantasmas dos escorregas e dos baloiços vazios, obriga a um questionamento irónico da posição central destas mulheres (invisibilidade), sem, no entanto, permitir que o espectador desvie delas por completo a atenção (visibilidade), já que são realmente as únicas personagens que se encontram em palco. A definição que Linda Hutcheon apresenta da utilização de ironia pelos discursos subalternos, ajuda a entender o carácter perturbador da alternância visibilidade/invisibilidade nesta peça: "o jogo a múltiplas vozes do que é dito e desdito e que permite ironizar a voz univoca do discurso autoritário" (Hutcheon 1994: 202 t.m.). 0 "discurso autoritário" aqui seria o patriarcal e as "vozes múltiplas", as femininas, que questionam e obrigam a um distanciamento relativamente a este discurso, dizendo e desdizendo a centralidade das personagens femininas e enfatizando a dificil visibilidade das mulheres na sociedade em geral.

0 "jogo a múltiplas vozes" assume outras dimensões irónicas ainda no segundo interlúdio e também no interlúdio final. No segundo interlúdio, as mulheres que começam por "realisticamente" trocar experiências pessoais, passam sem aviso prévio à repetição mecânica de frases que fazem lembrar o conteúdo de uma qualquer revista "feminina". 0 discurso que inicialmente era individual transforma-se em colectivo e o interlúdio termina com as mulheres transformadas em coro. As falas sincronizadas das personagens femininas figuram aqui como uma revisitação irónica do coro da tragédia clássica. Se um coro grego seria o mecanismo através do qual o dramaturgo procuraria expressar a consciência colectiva de uma determinada sociedade, este pseudo-coro transforma as mulheres que o compõem em robots ou máquinas-falantes pré-programadas pela sociedade patriarcal para dar voz a uma determinada ideia de feminilidade que aparece falsamente como sua. Diz-nos ainda Irigaray no mesmo artigo: "'feminilidade' é um papel, e uma imagem, um valor, um valor imposto às mulheres por sistemas masculinos de representação. Neste disfarce de feminilidade a mulher perde-se a si própria, e perde-se por explorar a sua feminilidade" (Irigaray 1985: 84). Ao se conformarem com uma noção de feminilidade construida a partir de coordenadas masculinas, estas mulheres encontram-se numa posição de subordinação relativamente ao sujeito 

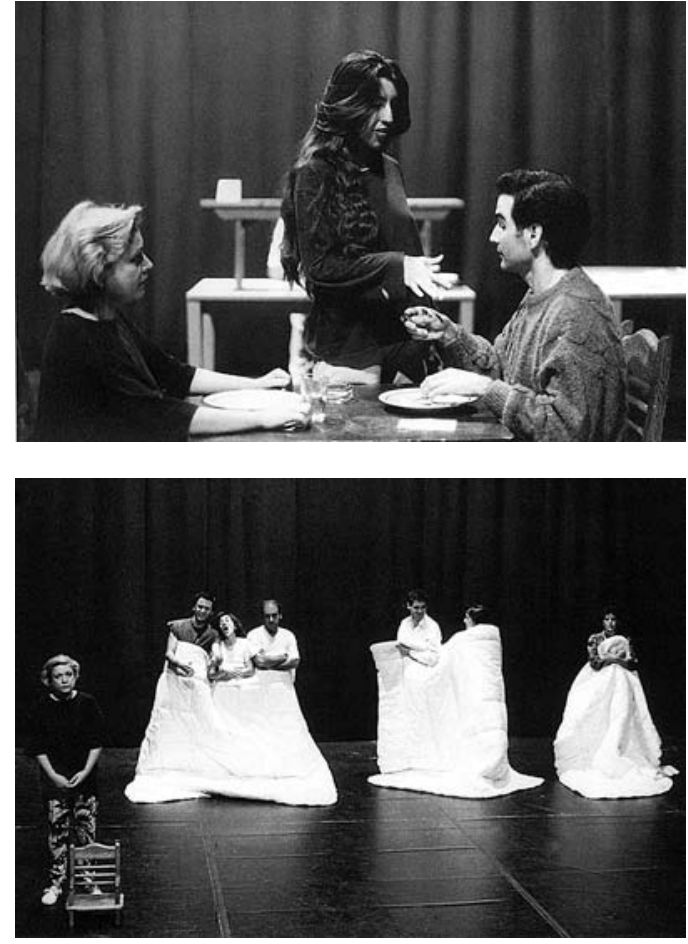

masculino e de inviabilização da sua própria posição enquanto sujeito, mas não sem antes dominarem fisicamente o palco e dele eliminarem quaisquer resquícios da presença masculina.

0 terceiro interlúdio traz-nos ainda um outro caso de (in)subordinação feminina. No último interlúdio, quatro mulheres visitam a Décima Quarta que teve o seu primeiro filho e que aguarda com ansiedade "há três dias" a visita do seu marido. Rapidamente, a centralidade da Quarta Mulher é substituida por uma discussão entre outras quatro sobre os maridos de cada uma e daí prossegue para outros temas "femininos" (beleza, dietas, telenovelas). Ironicamente, a discussão das mulheres só termina com a chegada dos tão aguardados visitantes (homens), que ao entrarem em palco proclamam como sua a tarefa de defenderem os direitos das mulheres. As personagens masculinas apresentam-se ao público e os seus nomes são os de importantes personalidades da história portuguesa (dos séculos XV e XVII): Bartolomeu Dias, Tristão Vaz Teixeira, Diogo Cão e Manuel Bernardes. Estas personagens, embora sejam as únicas personagens masculinas que aparecem nos três interlúdios, servem para enfatizar o estatuto do anonimato feminino. As mulheres sem nome (que povoaram a totalidade deste e dos dois outros interlúdios) nada podem contra o discurso patriarcal que as exclui da memória colectiva e histórica.

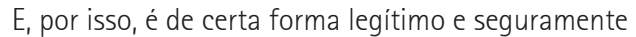
irónico, que estes homens se afirmem como os únicos que se encontram em condições de proclamar os direitos das mulheres e de promover a sua libertação. É a estes que é dado o privilégio de se expressarem livremente dentro do discurso patriarcal e de finalizarem o interlúdio, impossibilitando que o mesmo se passe com as personagens femininas, ainda que sejam elas que efectivamente falem a maior parte do tempo.

Em conclusão, se são realmente as mulheres que são visiveis nos três interlúdios da peça, só lhes é permitido aparecer se diluírem a sua identidade para dar lugar a

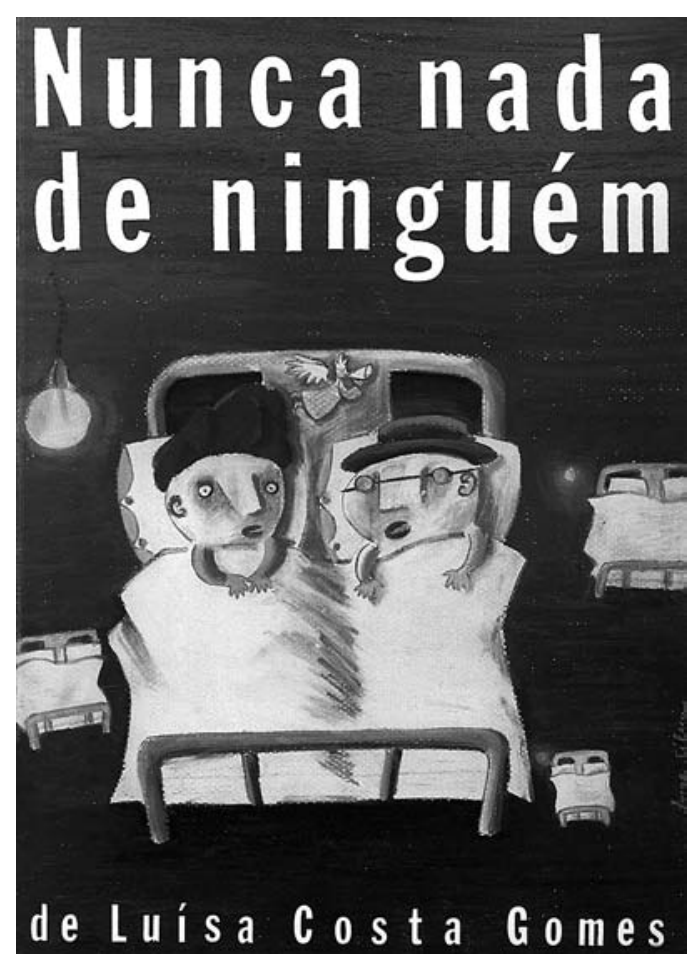

outras personagens fora do palco. É justamente neste paradoxo que residem os problemas da visibilidade das personagens femininas de Nunca nada de ninguém, mas simultaneamente a garantia da sua presença na memória do espectador. Costa Gomes é capaz de sublinhar no seu texto a invisibilidade a que é confinado o sexo feminino numa sociedade patriarcal, aplicando às mulheres as mesmas ideias elaboradas pela lógica masculina mas com uma diferença: a autora expõe a invisibilidade feminina no discurso patriarcal, "sem" tornar as suas próprias personagens invisiveis (e, por isso, esquecidas por um público formado pelos padrões masculinos de representação), através da criação de um espaço irónico entre o que vemos em palco (um grande número de personagens femininas) e os únicos papéis que são permitidos às mulheres (secundários). Esta representação irónica de figuras pseudo-poderosas torna visivel o que deveria permanecer invisivel, ao expor os papéis impostos às mulheres dentro e fora dos palcos.

Referências bibliográficas

DIAMOND, Elin (1988), "(In)visible bodies in Churchill's theatre", Theatre Journal, 40.2 (May), 188-204.

GOMES, Luisa Costa (1991), Nunca nada de ninguém, Lisboa, Edições Cotovia.

HUTCHEON, Linda (1994), Irony's Edge: The Theory and Politics of Irony, London: Routledge.

IRIGARAY, Luce (1985), "The power of discourse and the subordination of the feminine", in This Sex which is not One, Ithaca: Cornell U.P, pp.68-85.

PEREIRA, Vanessa Silva (2006), Voicing the Invisble: Gender, Character and Discourse in Luisa Costa Gomes and Caryl Churchill, Manchester, Universidade de Manchester (texto policopiado). 